\title{
Assessment of Nurses Knowledge and Practice about Peripherally Inserted Central Catheters at Neonatal Intensive Care Units
}

\author{
Omnia Yasser Ibrahim Ibrahim Saltah1 and Fawzia Elsayed Abusaad \\ 1(Registered Nurse at Pediatric Hospital, Mansoura University, Egypt) \\ 2(Professor of Pediatric Nursing, Faculty of Nursing,, Mansoura University, Egypt)
}

\begin{abstract}
The peripherally inserted central catheters (PICCs) have become among the most common technologies employed in the intravenous therapy of neonates as they allow safe long-term intravascular access, comfort, and ease of transition to home therapy that contributed to the increased survival of those newborns. Aim: Assess the nurses' knowledge and practices about peripherally inserted central catheter at neonatal intensive care units Method: Descriptive research was conducted on 45 neonatal nurses working at neonatal intensive care units affiliated to Mansoura University Children Hospital (MUCH). Peripherally inserted central catheter insertion questionnaire sheet and observational checklistwas used to collect data. Results: Most studied nurses had poor knowledge and the minority had average knowledge about PICC line care for neonates. Also, more than half of nurses had competent score regarding PICC line insertion and care. Conclusion: There was variation regrading neonatal nurses' knowledge and practices regarding PICC line insertion and care. Recommendation: A regular educational program about PICC line care should be consistent for neonatal nurse
\end{abstract}

Keywords: Assessment, knowledge, Practice, Neonatal nurse, Peripherally inserted central catheter (PICC)

\section{Introduction}

At Neonatal Intensive Care Unit (NICU) the use of PICCs considered as a one of new technologies that increased life span of the newborns, taking into consideration that neonatal co-morbidity and mortality has a direct effect on the preterm (intrauterine fetal age less than 37 weeks) newly born with low body weight (less than 2,5 kg) (Bhargava, Broccard, Bai, Wu, Dincer\& Broccard, 2020).

Choosing of this access should depend on the assessment of clinical staus of the newborn and the treatment aim, because it permits the access to administer two medications incompatible with each other, avoiding many venous access and decreasing the frequency of veinpunctures (Moureau\& Chopra, 2016). PICCs are the most commonly requested procedure in most interventional radiology departments (IR) nowadays, according to the statistical record of Mansoura University Children Hospital, there has been a steady increase in the number of PICC 
lines requested between 2009 to 2019 until now. The incidence ranged from $11 \%$ to $70 \%$ of the peripheral IVs inserted annually, affecting over $85 \%$ of hospitalized neonates in the intensive care units (Pereira Ferreira, et al. 2020).

Although PICCs are generally considered safe devices, they are associated with the numerous complications that can occur at the time of PICC insertion, including injury to nerves and vessels as well as catheter malposition. Additionally, there are multiple complications that can occur following placement, including line infections, line migration, and venous thrombosis, stenosis and catheter fracture(Sudprasert,Porntheerapat\&Pi sittakarne, 2019). A comprehensive and details patient history is necessary to avoid potential complications, however PICCs are contraindicated in neonate with frequent vomiting or coughing which can induce alternation in internal thoracic pressure causing catheter malposition, erosion or cardiac tamponade. As well as it must not be inserted in the presence of infected and impaired skin integrity at the insertion site that may be strong risk factor a bacterial infection. A need to find healthy site to insert the intravenous access away from area of skin that already has a bacterial problem (Clemence\&Maneval, 2019).

A number of strategies have been proposed to minimize the occurrence of complications associated with PICCs and leading to the good prognosis .Some strategies include antimicrobialimpregnated PICCs for prevention of central line-associated blood stream infection (CLABSI), and differences in catheter valve technology (in which, valved catheters may prevent catheter occlusion by preventing reflux of blood into the catheter relative to nonvalved catheters) and catheter flushing agents to potentially reduce catheter occlusion and line infection (Gonzalez, \&Cassaro, 2019).

A special team that characterized by professional experience and knowledge to improve good quality of care for newborns is required. Neonatal nurses are responsible for access insertion, daily care, early detection and management of complications related to access insertion and using. However, recent developments in the area of PICC insertion and it's associated complications prevention and management have focused on education, the neonatal nurses must be educated and have competent skills in the insertion of intravascular catheters, use appropriate infection control measures to avoid / prevent intravascular catheter-related infections and consequently achieve positive pediatric patient outcomes (Hashimoto, Maruyama, Fukuta, Tanaka,\&Omura, 2017). .

Neonatal intensive care units (NICUs) routinely utilize peripherally inserted central catheters (PICCs) to provide nutrition and long-term medications to premature and full-term infants. While there has been much growth in understanding PICC practices and outcomes in adults, less has been learned in pediatric and neonatal populations. This leaves knowledge gaps regarding practice for neonates who are the smallest and most vulnerable (Sharpe,Kuhn,Ratz, Krein\& Chopra, 2017).

This study aimed to:

Assess nurses' knowledge and practices about central catheter inserted peripherally at neonatal intensive care units. 
Research question:

What are the nurses' knowledge and practices about central catheter inserted peripherally at neonatal intensive care units?

Subjects and Method:

- Technical design:

\section{Research design}

Descriptive research deign was used to conduct this study.

\section{Settings}

The research was performed at theNeonatal Intensive Care Units (NICU) at Mansoura University Children Hospital (MUCH), which provides health services to neonates from Mansoura and the surrounding areas at Dakhlia governorate. NICU consist of 21 incubators in 5 rooms ( 3 rooms consist of 12 incubators for ICU care and 2 rooms consists of 9 incubators for ordinary care).

\section{Subjects:}

A convenience sample of (45) neonatal nurses at the previous mentioned setting who were providing care for neonates in neonatal intensive care units during the periods of data collection regardless their age, qualification, years of experience and willing to participate voluntarily with a purposive sample of (20) neonates admitted to NICU throughout six months and need PICC line insertion was enrolled in the study.

Tools of Data Collection:

Tool 1: Peripherally inserted central catheter insertion questionnaire

It was developed by the researcher after reviewing related literature to assess the nurses' knowledge about the PICC line insertion, its care and how to prevent its complication Dougherty, L. (2014), Velissaris, Lagadinou, Karamouzos, Marangos, Pierrakos, (2019). Questions were in the form of close ended questions to collect data about the following:

Part I: Characteristics of studied nurses (5items) such as age, gender, educational level, years of experience and previous attendance of training program about the PICC line.

Part II:Neonatal Nurses Knowledge about the PICC line(prepost Formate) composed of (32) questions about definition of the PICC line, indications, most common insertion sites, and precaution during insertion. Care of PICC line, complications, catheter removal and prevention of its complications.

\section{Scoring system:}

Each complete/ correct answer of knowledge was given (2) marks, the correct incomplete answer was given (1) mark and (0) mark if not known. Total score of knowledge was obtained, and then converted to a percent score. Total knowledge scores of nurses about the PICC line were (64) marks. The total level of nurses knowledge about the PICC line was categorized according to ( Hegazy\&Abusaad, 2019) into:

- Good knowledgefor score more than $75 \%$ ( $>48$ score)

- Average knowledgefor score $75 \%$ - 60\% (38.4- 48 score)

- Poor knowledgefor score less than $60 \%$ ( 0- 38.3 score)

Tool II: PICC line insertion and care observational checklist

This tool was adapted from (Bowden, et al (2016), Westergaard, Classen, \& Walther-Larsen, (2013),Delarbre, et al. (2014) ). The observation checklists were used to assess and evaluate the pediatric nurses' practice about the insertion technique (20 items), PICC site care and dressing change (13 items), maintaining patency 
of the PICC (5 items) and removal technique (29 items).

\section{- Scoring system:}

Scores were used to evaluate nurses practice in which each step of practice done correctly was given (2) marks, (1) mark if done incorrectly and (0) mark if not done. Total practices of nurses were divided according to (Hegazy, et al. 2019) into:

- competent practice if the nurse had score more than 75\% (100.5- 134 score)

- incompetent practice if the nurse had score less than 75\% (0-100.4 score)

\section{II - Operational design}

- Preparatory phase

This phase included a review of the past and current related literature and studies, using available books, magazines and articles to get acquainted with the various aspects of the study research problem and develop the study tool.The researcher prepared the guiding booklet. It was specially designed to meet the needs of nurses in a simple Arabic language. A panel of 5 experts in the field of nursing has evaluated and revised the content validity of the study tools for their clarification, sequence of items and content relevance. The required modifications were done, according to their suggestions. The internal consistency of the study tools was tested by using Cronbach's alpha coefficient test; $r=0.82$ for tool $\mathrm{I}, \mathrm{r}=$ 0.71 for tool II,

\section{2 -Exploratory phase Pilot study:}

A pilot study was carried out on 5 nurses $(10 \%$ of the participants) in order to assess the clarity, feasibility and applicability of the tool. No modifications were done consequently, therefore the pilot study were included in the study sample.

\section{Field work:}

The actual field work started after an approval that was obtained to conduct the study from the Director of MUCH to facilitate data collection. Once the permission was granted to proceed in the study. The researcher introduced herself to the nursing staff and explaining the study aim in brief. The researcher attended five days per week in the study setting at morning and afternoon shift. Each nurse was interviewed individually to collect nurses' data base line, their knowledge about the peripherally inserted central catheterusing tool I. Nurses' practices about PICC line insertion technique, PICC site care and dressing change, maintaining patency of the PICC and removal technique using tool II.

\section{III - Administrative design}

An official approval was achieved from the Research Commission from Faculty of Nursing, Mansoura university to hold out the study. A letter was submitted from the researcher to the Director of MUCH to obtain a permission to apply the research study.

\section{Ethical considerations:}

After describing the aim of the research, informed oral consent was obtained from each nurse for her participation. Anonymity and confidentiality of collected data were enssured and used only for research purposes. Participants were informed that participation in the study is voluntary and they have the right to withdraw from the study at any time freely with none responsibilities.

\section{V-Statistical design}

The collected data was coded and inserted into a data file using the Excel program for Windows. Frequency 
Assessment of Nurses Knowledge and Practice ...

analysis and manual review were used to detect errors. After full insertion, the raw data were introduced into the version of the Statistical Social Science Package (SPSS) by which the analysis was carried Table (1): Percentage distribution of the participating nursing staff based on their characteristics:

\begin{tabular}{|c|c|c|c|}
\hline \multirow{2}{*}{\multicolumn{2}{|c|}{ Nurses' characteristics }} & \multicolumn{2}{|c|}{$\mathrm{No}=45$} \\
\hline & & No. & $\%$ \\
\hline \multirow{4}{*}{ Age /year } & $20-<30 y s$ & 22 & 48.9 \\
\hline & $30-<40 y s$ & 14 & 31.1 \\
\hline & $\geq 40 \mathrm{ys}$ & 9 & 20.0 \\
\hline & Mean \pm SD & \multicolumn{2}{|c|}{$32.28 \pm 5.03$} \\
\hline \multirow[b]{2}{*}{ Sex } & Male & 4 & 8.9 \\
\hline & Female & 41 & 91.1 \\
\hline \multirow[b]{2}{*}{ Educational Level } & Nursing Technical Institute & 8 & 17.8 \\
\hline & Bachelor Degree & 37 & 82.2 \\
\hline \multirow{4}{*}{ Years of Experience } & $1-<5 y s$ & 13 & 28.9 \\
\hline & $5-<10 y s$ & 8 & 17.8 \\
\hline & $\geq 10$ ys & 24 & 53.3 \\
\hline & Mean \pm SD & \multicolumn{2}{|c|}{$6.94 \pm 3.80$} \\
\hline \multirow{4}{*}{ Previous attendance of training program } & None & 24 & 53.3 \\
\hline & One course & 15 & 33.3 \\
\hline & Two course & 4 & 8.9 \\
\hline & Three and more & 2 & 4.4 \\
\hline
\end{tabular}

Figure(1)Percentagedistribution of the participating nursing staff based on their previous attendance to training program about peripherally inserted central catheter.

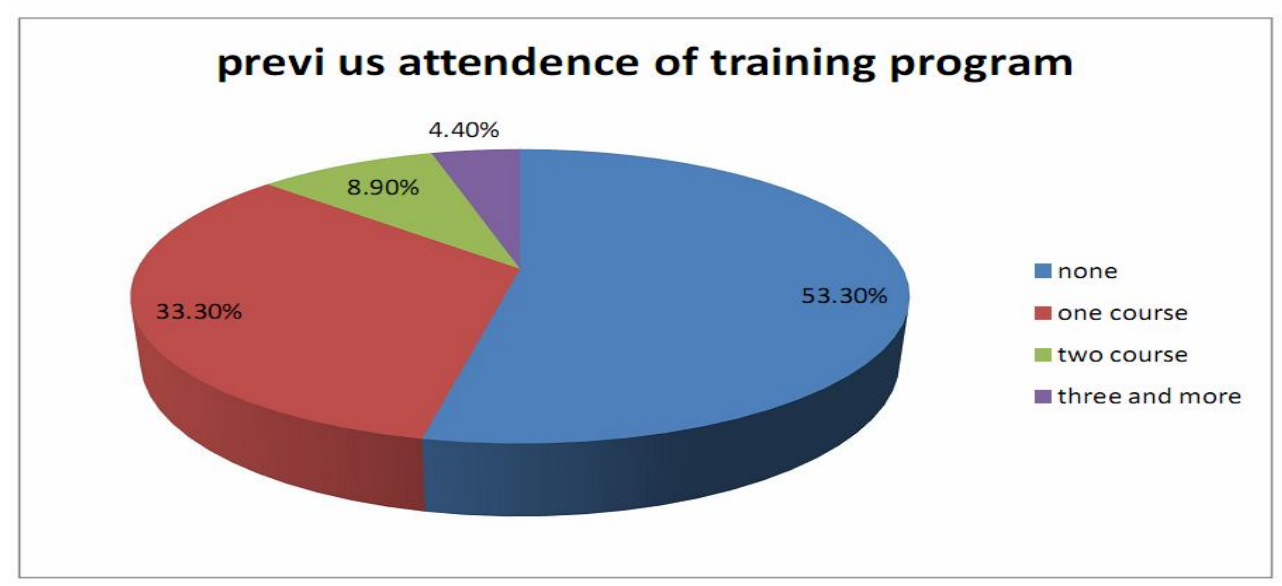

out with the application of frequency and percentage. The data has been revised, coded and analyzed.Qualitative data were presented as percentand number Results: 
Omnia Yasser Ibrahim Ibrahim Saltah1 et. al.

Table (2): Percentage distribution of total nurses' knowledge score about PICC line

\begin{tabular}{|c|c|c|}
\hline Level of Knowledge & No & \% \\
\hline Good knowledge & 0 & 0.0 \\
\hline Average knowledge & 2 & 4.4 \\
\hline Poor knowledge & 43 & 95.6 \\
\hline Total score Mean \pm SD & \multicolumn{2}{|c|}{$31.13 \pm 5.056$} \\
\hline
\end{tabular}

Table (3): The mean scores of the studied nurses' performance to PICC line insertion and care

\begin{tabular}{|l|c|}
\hline \multicolumn{1}{|c|}{ Practical Skills Items } & Mean ScoresMean \pm SD \\
\hline 1. Insertion Technique & $30.54 \pm 12.31$ \\
\hline 2, Site care and dressing change & $16.22 \pm 6.32$ \\
\hline 3.Maintaining patency of PICC line & $5.98 \pm 1.87$ \\
\hline 4.Removal of PICC line & $25.18 \pm 7.19$ \\
\hline $\begin{array}{l}\text { Total score } \\
\text { Mean } \pm \text { SD }\end{array}$ & $80.044 \pm 6.71$ \\
\hline
\end{tabular}

Table (4): Percentage distribution of the total practice score of studied nurses to PICC line insertion and care.

\begin{tabular}{|c|c|c|}
\hline Total practice category & \multicolumn{2}{|c|}{} \\
\cline { 2 - 3 } & No & \% \\
\hline Competent & 24 & 53.3 \\
\hline Incompetent & 21 & 46.7 \\
\hline
\end{tabular}

Table (1) showed that, $48.9 \%$ of the studied nurses aged from 20 to less than 30 years old with mean age of $32.28 \pm 5.03$ years. The majority of them (91.1) were female and $82.2 \%$ of them were bachelor's degree of nursing. As regards to years of experience, more than half $(53.3 \%)$ of the studied nurses had more than 10 years of working in the Neonatal intensive care unit (NICU). In addition, more than half of them $53.3 \%$ did not receive any training program about PICC line.

Figure (1) showed that $33.3 \%$ of nurses attend one course about PICC line and only $4.4 \%$ attend three and more courses.

It was clear from table (2) that $95.6 \%$ of studied nurses had poor knowledge and $4.4 \%$ had average knowledge about PICC line care for neonates.

Table (3) showed that, the mean score of the studied nurses' total performance to insertion and care of PICC line was $80.044 \pm 6.71$.

As regard total practice level of studied nurses to PICC line insertion and care, table (4) indicated that more than half of nurses $(53.3 \%)$ had competent level and less than half of them had incompetent level of practice.

Discussion:

Neonatal intensive care units (NICUs) routinely utilize peripherally inserted central catheters (PICCs) to provide nutrition and long-term medications to pre-mature and full-term infants (Sharpe,et al., 2017). The survival of an increasing number of verylow birth weight and critically ill neonates heightens the need for peripheral inserted central catheter to administer parenteral nutrition that support growth, as well as intravenous fluids and medications. As a result, nurses are continually being challenged to improve the methods by which they provide safe and consistent vascular 
access to those vulnerable populations. (Chopra,Ratz, Flanders \& Krein, 2016 ). Few studies about the use of PICC lines in neonatology and pediatrics were found in the last 10 years, especially in terms of procedure and care (Nobre , Cardoso, Teixeira, Lopes, Fontenele ,2016). So, the aim of this study is to study the effect of implementing educational program about PICC on nurses' knowledge, practice and neonatal outcomes.

The results of the present research showed that nearly half of the participant nursing staff belonged to the age group 20 and less than 30 years and majority of them were female (table1). This finding was in line with (Se \& LS, 2016). who found in his study about "Nurses' Knowledge and performance concerning to Peripheral Intravenous Catheter Care" $45(54 \%)$ respondents aged between 21 26 years, and $39(46 \%)$ who were more than 26 years. Also, Xu, Zhang, Hou, Ma , Gong, Tang, 2020) made study about 'Nurses' information regarding peripheral central catheter nursing care and its effects on keeping it patent, China: a cross-sectional survey" found that the largest age group average among 25 and $34(51.6 \%)$, followed by those aged less $25(30.9 \%)$. . Also, a study conducted by Deshnukh \& Shinde (2014) about " Impact of Structured Education on Knowledge and Practice Regarding Venous Access Device Care among Nurses " in India and found that $70 \%$ were in the age group of 21$30 y e a r s$ and $83.3 \%$ were females. These results may because study of nursing in Egypt universities was exclusive for females only till few years ago; this fact attributes the high proportion of females.

Concerning educational level of studied nurses the current results clarified that most of them had bachelor degree.
From the researcher point of view this finding may be due to head nurse of NICU requesting large number of highly qualified nurses always and the governmental tendency for highly qualified nurses working in ICU which emphasize the fact Bachelor degree nurses recruited to care for critical care setting patients. This results contradicted with Se et al. (2016) who found that most of the participant (60; $71 \%$ ) possessed Diploma in Nursing, and 24 (29\%) held Bachelor of Nursing.

As regards to years of experience, more than half of the studied nurses had more than 10 years working in the Neonatal intensive care unit. This result was contradicted with Deshnukh, et al. (2014) who found that the most of the participants $71.67 \%$ had less than 5 years of clinical experience. Also, Issa, Elmadwah, Al Mosawi (2018) who conducted a study about "Evaluation of Nurse's Knowledge in Management of Premature Baby in Neonatal Units" revealed that near one third of the studied nurses were having one to five years of experience. As well as, Mohammed and Abdel Fattah (2018) reported that more than half of the participants had between first and fifth years of experiences.

The current research showed that more than half of nursing staff did not receive any training program concerning PICC. This finding may be due to a number of nurses are recently experienced at the neonatal intensive care unit and they haven't had the opportunity to attain training programs because of workload atNICU. The finding is in an agreement with Mohammed, et al., (2018) and revealed that, two thirds had not attained any previous training courses. Similarly, a study implemented by Abd El- Aal (2018) showed that, the majority of the studied nurses did not attain any previous training courses related to neonatal care. 
Also, Xu ,Zhang, Hou, Ma, Gong \& Tang, (2020) found in his study that Less than half of the participants $(44.6 \%)$ received PICC previous training.

According to total nurses knowledge level about PICC before and after educational program implementation, the current results revealed that majority of studied nurses had poor knowledge before program implementation while after program more than half of them had average level of knowledge with a statistical significance in total score of nurses knowledge before and after educational program $(\mathrm{p}=0.007)$ (table 2). This results accordance with Kun, et al. (2017 )who study "Effect of specialty training on nursing staff's KAP on PICC and catheter maintenance" in china found improvement in the knowledge, attitude, and skills on PICC prior training are very low which means that the nurses are had no enough knowledge regarding PICC before training, which significantly improved after intervention showing that the proper training improved their understanding on the physical structure of human blood vessels, standardize their technique, and allow the nurses to have a professional experience in PICC catheterization. Also, Deshmukh1, et al. (2014) who found that the $43.33 \%$ of participants their knowledge was poor before the intervention which became good knowledge score after the post-test. As well as, there was improvement in the mean score of knowledge during the post test compared to pre test. Also, a study by Hadaway (2012) about needle stick, short peripheral catheters, and health care team risks" means that nurses had poor standard skills and knowledge of PIC care affects patients' safety risks and outcomes directly.

Concerning nurses' performance to PICC insertion and care before and after educational program, the results indicated that the mean score of studied nurses performance to insertion technique, site care with dressing change, maintaining patency and removal of PICC was higher after educational program implementation than before with statistical significant difference regarding insertion technique, site care and dressing change and maintaining patency of PICC line mean score before and after program implementation $(p>0.05)$ (table 3) .From the researcher view it is necessary to improve experience that help nurses to satisfy the special demands of infants in the use of catheters placed in peripheral vein that consequently reduce the occurrence of adverse events during hospitalization. This results come in the line with $\mathrm{Xu}$ (2020) results that indicated that the nurses' level of mastery concerning different dimensions was different, followed by removal of the access $(0.81 \pm 0.117)$, PICC flushing and locking $(0.76 \pm 0.222)$ and complication management $(0.71 \pm 0.167)$.

In addition to this Sharpe, Pettit , Ellsbury (2013) who made study about "A national survey of neonatal central catheter peripherally placed (PICC) practices" reported that wide difference of PICC performance in many aspects of PICC placement and care. The highest level of conformity was noticed with the following practices: use of two nursing staff to perform a catheter care, trimming the PICC, using a kit including insertion supplies, personal protective equipments and $\mathrm{ub}=$ niversal precautions during insertion, catheter tip residing in the superior vena cava for upper body insertions, and not heparin locking, infusing blood products, performing catheter repair, or inserting.

As regards nurse level of competency before and after educational program implementation, the present results clarifies that less than half of 
studied nurses had incompetent performance level (table 4). This results in the line with Deshmukh1 et al., (2014) who found that the maximum of $75 \%$ of subjects scored between 14-17 (Average) practice score in the pre-test before structured education. Also, this results congruent with study of Woody and Davis (2013) about "Increasing Nurse Competence in Peripheral Intravenous Therapy" and found that insertion and maintenance of the PIC are considered essential nursing skills for all practicing nurses.

\section{Conclusion:}

Depend on the finding of the present research, it was concluded that, most studied nurses had poor knowledge and the minority had average knowledge about PICC line care for neonates. Also, more than half of nurses had competent score regarding PICC line insertion and care.

Recommendation: The following recommendation is suggested:

- Nursing staff should be encouraged and take the chance to attend continious nursing education to gain more information about to the last updated nursing practice guidelines and improve their information about PIC care

- Standardized guidelines for dealing with PICC associated complication must be available for all nursing staff at NICU.

\section{References}

- Abd El-Aal, N. (2018). Effect of self-development program on nurses' performance regarding quality standers of neonatal care. Doctoral thesis, Mansoura University, Egypt, 139.

- Bhargava, M., Broccard, S., Bai, Y., Wu, B., Dincer, E. H.,
\&Broccard, A. (2020). Risk factors for peripherally inserted central catheter line-related deep venous thrombosis in critically ill intensive care unit patients. SAGE Open Medicine, 8, 2050312120929238

- Bowden, V.R., Greenberg, C.S., (2016). Pediatric Nursing Procedures. 4th Ed, Wolters Kluwer, Philadelphia, Baltimore. pp: (360-363).

- Chopra V, Kuhn L, Ratz D , Flanders SA, Krein SL( 2016). Vascular nursing experience, practice knowledge, and beliefs: results from the Michigan PICC1 Survey. J Hosp Med. ; 11 ( 4 ): 269-275 .

- Clemence, B.J., Maneval, E.M. (2014) Risk factors associated with catheter -related upper arm extremity deep Vein thrombosis in patients with Peripherally Inserted Central Venous catheters. Part 1. Infusion Nurses Society. Vol 37.No 3.

- Delarbre, B., Dabadie, A., Stremler-Lebel, N., Jolibert, M., Cassagneau, P., Lebel, S., ...\& Petit, P. (2014). Introduction of the use of a pediatric PICC line in a French University Hospital: review of the first 91 procedures. Diagnostic and interventional imaging, 95(3), 277-281.

- Deshmukh, M., Shinde, M. (2014). Impact of Structured Education on Knowledge and Practice Regarding Venous Access Device Care among Nurses. International Journal of Science and Research (IJSR) 3(5): 895-901

- Dougherty, L. (2014). Frequency, Diagnosis, and 
Management of Occlusive and Mechanical PICC Complications. In S. Sandrucci\& B/ Mussa (Eds.). Peripherally Inserted Central Venous Catheters, (pp. 85-94). New York: Springer.

- Gonzalez, R., \&Cassaro, S. (2018). Percutaneous Central Catheter (PICC). In StatPearls [Internet]. StatPearls Publishing.

- Hadaway, L.C.( 2012). Needlestick injuries, short peripheral catheters, and health care worker risks. J InfusNurs 35(3): 164-78.

- Hashimoto, Y., Maruyama, J., Fukuta, T., Tanaka, T., Omura, H., (2017), Experience of Peripherally Inserted Central Venous Catheter in Patients with Hematologic Diseases, Internal medicine Journal, Japan, vol.56(4), 386-395.

- Hegazy ,M, W \&Abusaad , E, F.(2019). Nurses, Knowledge and Practices about Care of Neonates on Mechanical Ventilators with Respiratory Distress.International Journal of Novel Research in Healthcare and Nursing Vol. 6, Issue 1, pp. 223-231.

- HO , LIEW, TANG (2016). Nurses' Knowledge and Practice in Relation to Peripheral Intravenous Catheter Care. Med \& Health 2016; 11(2): 181-188.

- Issa, S., AL Madwah, K., Al Mosawi, H. (2018). Evaluation of Nurse's Knowledge in Management of Premature Baby in Neonatal Units, The Basics of Nursing, Basrah Nursing College, Basrah University, Basrah, Iraq ,American Journal of Nursing Research, 6: ( 5), 291-295
- $\quad$ Kun C, Yan J, Suwen X, Yan L, Li X, Min S, Qian C, .\& Lulu $\mathbf{F ( 2 0 1 7 ) . ~ E f f e c t ~ o f ~ s p e c i a l t y ~}$ training on nursing staff's KAP on PICC and catheter maintenance. Biomedical Research; 28 (20): 9144-9147.

- Mohammed, A., \& Abdel Fattah, S. (2018). The effect of educational program on nurse's knowledge and practices about nasogastric tube feeding at neonatal intensive care units Ain Shams University, Cairo, Egypt, Journal of Nursing Education and Practice, 8: (8),79

- Moureau N, Chopra V(2016). Indications for peripheral, midline and central catheters: summary of the MAGIC recommendations. $\mathrm{Br}$ J Nurs. Apr 28-May 11;25(8):S15-24. doi: 10.12968/bjon.2016.25.8.S15.

PMID: 27126759.

- Nobre KSS, Cardoso MVLML, Teixeira JL, Lopes MMCO, Fontenele FC. (2016) Use of peripherally inserted central catheter in a neonatal unit: a descriptive study. Online braz $\mathrm{j}$ nurs [internet] Jun [cited year $\begin{array}{lll}\text { month day]; } 15 & \text { (2):215-225. }\end{array}$ Availablefrom:http://www. objnursing.uff.br/index.php/nursin g/article/view/5420 .

- Pereira Ferreira, C., LemosQuerido, D., Moreira Christoffel, M., Saraiva de Almeida, V., Andrade, M., \& Camilo Leite, H. (2020). The use of peripherally inserted central venous catheter in the Neonatal Intensive Care Unit. RevistaEletronica de Enfermagem, 22. 
- Sharpe E, Kuhn L, Ratz D, Krein S, Chopra V. (.2017) Neonatal Peripherally Inserted Central Catheter Practices and Providers, Advances in Neonatal Care • Vol. 17, No. 3 • pp. 209-221.

- Sharpe E. Pettit J, Ellsbury D (2013). A national survey of neonatal peripherally inserted central catheter (PICC) practices. Advanced Neonatal Care. Feb;13(1):55-74.

- Sudprasert, C., Porntheerapat, N., \&Pisittakarne, N. (2019). The Effect of Knowledge Management Program of Nurses for practice on Pediatric Patient with Central Venous Catheters Care Guidelines at Pediatric's Surgical Ward. Journal of the Department of Medical Services-, 44(3), 47-51.

- Velissaris, D., Lagadinou, M., Karamouzos, V., Marangos, M., Pierrakos, C., (2019), Peripheral Inserted Central Catheter Use and Related Infections in Clinical Practice: A Literature Update, Journal of clinical medicine research, vol.11(4), 235-244.
- Westergaard, B., Classen, V., \& WALTHER-LARSEN, S. (2013). Peripherally inserted central catheters in infants and children-indications, techniques, complications and clinical recommendations.

ActaAnaesthesiologicaScandinavi ca, 57(3), 278-287.

- Woody G and Davis B, (2013). Increasing Nurse Competence in Peripheral Intravenous Therapy .Journal of infusion nursing: the official publication of the Infusion Nurses Society 36(6):413-9.

- Xu B, Zhang J, Hou J, Ma M, Gong Z, Tang S. (2019). Nurses' knowledge of peripherally inserted central catheter maintenance and its influencing factors in Hunan province, China: a cross-sectional survey.BMj Open 2020;10:e033804. doi:10.1136/bmjopen—033804. 